\title{
Uma construção de fatos e palavras: Cícero e a concepção retórica da história*1
}

\section{A construction of deeds and words: Cicero and the rhetorical conception of history}

\author{
FeLIPE CHARBEL TEIXEIRA \\ Doutor em História pela Pontifícia Universidade Católica - Rio de J aneiro \\ fcharbel@uol.com.br
}

\begin{abstract}
RESUMO 0 artigo analisa a concepção retórica da história tal qual exposta por Cícero no segundo livro do diálogo De Oratore. Argumenta-se que o entendimento da história como uma construção de fatos e palavras tanto enfatiza seu caráter retórico quanto o compromisso da história com a verdade, sendo que, para Cícero somente um orador prudente pode se mostrar capaz de produzir um texto digno de ser chamado "história", texto que simultaneamente deleite e produza em seus leitores e ouvintes lições de virtude.
\end{abstract}

Palavras-chave historiografia, retórica, Cícero.

* Artigo recebido em: março/2008.

1 Este artigo corresponde a parte do capítulo 3 de minha tese de doutorado - Timoneiros: retórica, prudência e história em Maquiavel e Guicciardini -, defendida em J unho de 2008 no Programa de Pós Graduação em História Social da Cultura da PUC-RJ, com orientação do Prof. Marcelo Gantus J asmin. Agradeço à CAPES pelo apoio financeiro no período. 
ABSTRACT The article analyses Cicero's rhetorical conception of historical writing, as exposed in De Oratore's second book. One argues that Cicero's comprehension of history as a construction of deeds and words emphasizes both its rhetorical character and its commitment to truth. According to Cicero only a prudent orator is able to create a text which may be called "history", a text which simultaneously delights and produces lessons of virtue to his readers and listeners.

Keywords historiography, rhetoric, Cicero.

Embora a história - entendida como prática de inquirição sobre as grandes e memoráveis obras dos homens calcada numa "atitude crítica com relação ao registro de acontecimentos", ${ }^{2}$ cujo propósito central seria 0 de salvar os feitos humanos do esquecimento ${ }^{3}$ tenha não apenas surgido na Grécia do V século como alcançado, com Heródoto e Tucídides, sua maior expressividade no mundo antigo, a discussão acerca da concepção retórica de história predominante na Antiguidade deve dar atenção especial às reflexões de Cícero no livro II do diálogo De Oratore, isto porque os gregos jamais chegaram a definir a história como um gênero retórico-poético. Porém, antes de discutir os preceitos ciceronianos sobre a escrita da história, dedicarei algumas páginas à análise da tensão entre logos e ergon na História da Guerra do Peloponeso de Tucídides, assim como ao exame da concepção de autópsia e do privilégio do testemunho ocular sobre os relatos orais predominantes entre os historiadores gregos, como forma de introduzir a discussão acerca da definição ciceroniana da história como exaedificatio in rebus et verbis.

Como nota Charles Fornara, a nomenclatura "historiador" era bastante imprecisa na Antiguidade, podendo ser atribuída a escritores de textos em prosa que lidavam com "aspectos da atividade humana e heróica no tempo passado". ${ }^{4}$ Havia, segundo o autor, cinco tipos básicos de abordagem dos feitos de outras épocas: genealogia, etnografia, história, história local e cronografia. ${ }^{5} \mathrm{~A}$ história, nesse sentido mais estrito, era compreendida como a descrição das ações humanas passadas - em suas acepções latinas,

2 MOMIGLIANO, Arnaldo. As raízes clássicas da historiografia moderna. Bauru: EDUSC, 2004, p.55. Segundo Santo Mazzarino, esta atitude crítica era, ao mesmo tempo, profundamente religiosa. Cf. MAZZARINO, Santo. II pensiero storico classico, vol. 1. Roma: Laterza, 2004, p.207.

3 Cf. HARTOG, François. O espelho de Heródoto. Belo Horizonte: Editora UFMG, 1999, p.22; CANFORA, Luciano. La storiografia greca. Milano: Bruno Mondadori, 1999, pp.26-43.

4 FORNARA, Charles. The Nature of History in Ancient Greece and Rome. Berkeley, Los Angeles \& London: University of California Press, 1988, p.3, nota 8.

5 Cf. FORNARA, Charles. The Nature of History in Ancient Greece and Rome, p.1. 
expositio rerum gestarum, memoria rerum gestarum ou simplesmente historia -, diferenciando-se da "história local" (próxima dos anais) por não se constituir necessariamente como registro ano a ano dos acontecimentos da polis desde sua fundação. Os limites e fronteiras entre as referidas formas de relato eram tênues, e os próprios gregos não demonstravam muito interesse em delimitar as particularidades de cada uma. Apenas Aristóteles será mais específico a esse respeito, ao diferenciar, na Poética, a história da poesia. ${ }^{6}$

Na abertura da História da Guerra do Peloponeso lê-se que "Tucídides de Atenas escreveu a guerra dos peloponésios e atenienses, como guerrearam uns conta os outros". ${ }^{7}$ Escrever a guerra é diferente de escrever sobre a guerra; trata-se de uma maneira peculiar de conceber a relação entre logos e ergon, palavra ${ }^{8}$ e feito, pela simultânea constatação de uma "dificuldade de chegar à realidade das coisas" 9 inerente ao logos e da possibilidade de reduzir a equivocidade do relato a um mínimo, pelo recurso ao testemunho ocular - não os logoi dos que se arrogam suspeitas observações, mas as considerações do phronimos, homem diligente e prudente, o próprio Tucídides de Atenas, testemunha dos acontecimentos mais grandiosos e memoráveis que tiveram lugar na Hélade desde o fim da guerra de Tróia e por isso mesmo apto a elidir em sua exposição todo e qualquer desnível entre o que aconteceu e o que é apresentado discursivamente, compondo uma narrativa que é ela própria a presença da guerra, segundo o ideal do rigor (akríbeia). ${ }^{10}$

Como percebe Adam Milman Parry, a distinção entre logos e ergon constituiu uma característica central do "pensamento" grego, fazendo-se presente já em Homero e sendo percebida de maneiras particulares na poesia - onde ambas as categorias conformam aspectos dessemelhantes porém igualmente significativos da experiência humana -, na tradição popular - entendimento dos erga como "realidade inquestionável" e condenação dos logoi como puramente delusórios -, e na filosofia - especialmente em Parmênides e Heráclito, correspondendo o logos à "realidade verdadeira" e sendo o mundo sensível visto como simples "aparência ilusória". ${ }^{11}$ Ainda

6 Cf. ARISTÓTELES. Poética. São Paulo: Cultrix, 2005, IX, p.28.

7 TUCIDIDES. História da Guerra do Peloponeso, I, 1, p.3. Emprego aqui a tradução de J acyntho Lins Brandão. In: HARTOG, François (org.). A história de Homero a Santo Agostinho. Belo Horizonte: Editora UFMG, 2001, p.57.

8 Emprego o vocábulo "palavra", aqui, para caracterizar aquilo que J acques Derrida chamou de privilégio da phoné, em sua relação direta com o logos: "Tal como mais ou menos implicitamente determinada, a essência da phoné estaria imediatamente próxima daquilo que, no 'pensamento' como logos, tem relação com o 'sentido'; daquilo que o produz, que o recebe, que o diz, que o 'reúne'. [...] Entre o ser e a alma, as coisas e as afeções [affection], haveria uma relação de tradução ou de significação natural; entre a alma e o logos, uma relação de simbolização convencional. E a primeira convenção, a que se referiria imediatamente à ordem da significação natural e universal, produzir-se-ia como linguagem falada". DERRIDA, J acques. Gramatologia. São Paulo: Perspectiva, 2004, p.13.

9 PARRY, Adam Milman. Logos and ergon in Thucydides. Salem: Ayer Company, 1988, p.103.

10 Cf. MAZZARINO, Santo. Il pensiero storico classico, p. 250.

11 PARRY, Adam Milman. Logos and ergon in Thucydides, pp.15-16. "To understand its development properly, we must take account of three strands of thought in Greek literature of this period. These strands are often intertwined, and they do not appear with equal consistency throughout the period in question. Yet they can legitimately be con- 
segundo Parry, o capítulo 22 do livro I da História da Guerra do Peloponeso marca a primeira vez em que a distinção logos / ergon ocorre no texto de Tucídides. ${ }^{12}$ Diz 0 ateniense na referida passagem:

Quanto aos feitos realizados na guerra, decidi escrever não recolhendo informações junto de qualquer um, nem como me pareciam ser, mas os que eu próprio presenciei, tendo ainda checado cada um deles, com a maior exatidão possível, junto de outros. Com muito trabalho eles se descobriam, porque os presentes a cada um dos feitos não diziam as mesmas coisas sobre os mesmos, mas de acordo com a simpatia ou lembrança que tinham. ${ }^{13}$

Diferentemente de Heródoto, Tucídides, ao descartar os depoimentos orais diversos, procura estabelecer uma presunção da fidúcia em torno do seu testemunho ocular bem intencionado, cujo produto é apresentado não como uma interpretação particular, mas como a presença da coisa mesma - ${ }^{14}$ feitos memoráveis não apagados pela ação do tempo. ${ }^{15}$ Esta é, para o historiador ateniense, a condição de possibilidade para que seu relato possa se constituir como "aquisição [ktêma] para sempre", dotada de utilidade universal. ${ }^{16}$

Trata-se, nas palavras de Luciano Canfora, de uma "axiologia das sensações", sendo os sentidos privilegiados a visão e a audição. ${ }^{17} \mathrm{~A}$ proeminência da visão põe em segundo plano a discussão sobre a tensão entre logos e ergon, pois, desde que o historiador não queira ludibriar seus ouvintes / leitores, o relato proveniente de testemunho ocular assegurará a verdade (alétheia) da exposição, no sentido do desvelamento do que poderia ter-se ocultado rapidamente com a ação destrutiva do tempo. ${ }^{18}$ É nesse sentido

sidered as distinct attitudes toward a similar problem. One is a literary strand: that is, it appears first in the poets. Its tendency is to regard logos and ergon, or equivalents thereof, as differing but positive constituents of human experience. The second is popular. It appears first in Solon, then in the earliest comic writers. There is reason to think that it was common coin in the Vth century. It is simple and ethical, placing value on ergon as unquestioned reality, and condemning logos as something purely delusive. The third is philosophical, appearing first in Parmenides and - though less clearly - in Heraclitus. It regards logos as true reality, and puts in the category of the delusive appearances of the sensible world".

12 PARRY, Adam Milman. Logos and ergon in Thucydides, p.103.

13 TUCÍDIDES. História da Guerra do Peloponeso, l, 22, p.81.

14 Cf. GUMBRECHT, Hans-Urich. Production of Presence. What Meaning CannotConvey. Stanford: Stanford University Press, 2004, p.xiii. "The word 'presence' does not refer (at least does not mainly refer) to a temporal but to a spatial relationship to the world and its objects. Something that is 'present' is supposed to be tangible for human hands $[\ldots]^{\prime \prime}$.

15 Cf. TUCÍDIDES. História da Guerra do Peloponeso, I, 20, p.79.

16 A premissa da utilidade geral da história, sua compreensão como "aquisição para sempre", é a estabilidade da natureza humana e a recorrência de certos padrões perceptíveis nos acontecimentos.

17 CANFORA, Luciano. La storiografia greca, p.17. Discordo de Canfora, porém, quando este diz que "con l'esaltazione della vista, la storiografia rivela tutta la sua deboezza conoscitiva". Não se trata de uma debilidade, e sim, para falar como Hartog, de um regime de historicidade fundado em uma concepção distinta de verdade.

18 Como percebe Luiz Costa Lima, a partir da análise heideggeriana da questão, "alétheia, portanto, continha um duplo movimento, que não era sucessivo e não se esgotava ao atingir o segundo estágio: ocultar e desvelar. Essa alternância lhe será constitutiva. Acrescente-se para o caso particular da escrita da história: a reconstituição de uma cena passada desvela e ao mesmo tempo oculta, sem que isso dependa de alguma intenção de fraude de quem a empreende". COSTA LIMA, Luiz. História. Ficção. Literatura. São Paulo: Companhia das Letras, 2006, p.111. 
que deve ser compreendida a famosa assertiva de Collingwood de que, para os gregos, "em vez de ser o historiador a escolher o assunto, era o assunto que escolhia o historiador. Isto é, a história era escrita apenas porque tinham lugar acontecimentos memoráveis, que despertavam o aparecimento de um cronista". ${ }^{19}$

0 progressivo distanciamento em relação aos feitos, associado à multiplicação dos relatos, constitui entrave decisivo na luta contra o esquecimento; nesse sentido, a autópsia seguida de registro constitui o melhor remédio contra a ação do tempo. "A natureza", diz Políbio no livro XII das Histórias,

forneceu-nos dois instrumentos por meio dos quais sabemos muitas coisas e podemos averiguar outras. Refiro-me à visão e à audição; a vista é muito mais fidedigna, segundo o dito de Heráclito: os olhos são testemunhos mais exatos que os ouvidos. ${ }^{20}$

Isto porque, como diz Candolo a Gigés no livro I das Histórias de Heródoto, "os ouvidos são menos crédulos que os olhos". ${ }^{21}$

Políbio, prosseguindo seu exame dos dois "instrumentos" - visão e audição - , cita o caso de Timeu, que teria escolhido para suas investigações o método "mais agradável, porém menos válido", abrindo mão do testemunho ocular e valendo-se da audição, campo que comporta também a leitura. ${ }^{22}$ Neste último caso, é preciso que o historiador tenha o cuidado de "buscar uma cidade que possua documentação abundante ou que tenha em suas cercanias uma biblioteca", de modo a permitir o cotejo dos diferentes relatos". ${ }^{23}$ A comparação e exame cuidadoso das diversas posições analisadas fazem-se necessários, também, quando existem diferentes versões orais. É significativo, nesse sentido, que Heródoto, nas passagens de suas Histórias que tratam de acontecimentos já opacos na memória dos homens, seja extremamente cauteloso, evocando diversas posições e muitas vezes abstendo-se de tomar partido, enquanto os logoi de suas viagens não comportam este tipo de procedimento, sendo mais afirmativos. ${ }^{24} \mathrm{O}$ cotejamento de informações obtidas por meios orais ou pela leitura de livros não deve, porém, substituir a "investigação pessoal", como defende Políbio. ${ }^{25}$ "Éforo", diz ele, "afirma que se pudéssemos ser testemunhas de todos os acontecimentos, esta experiência seria muito distinta das outras". ${ }^{26}$

\footnotetext{
19 COLLINGWOOD, R. G. A idéia de história. Lisboa: Editorial Presença, 2001, p.42.

20 POLIBIO. Histórias. Madrid: Editorial Gredos, 1996, XII, 27, p.521.

21 HERODOTO. Histórias. São Paulo: Ediouro, sd, I, 8, p.32.

22 Cf. POLIBIO. Histórias, XII, 27, p.521.

23 Cf. POLIBIO. Histórias, XII, 27, p.522.

240 que se relaciona diretamente àquilo que Santo Mazzarino considera uma singularidade de Heródoto: sua tentativa de compreender também o ponto de vista persa. Cf. MAZZARINO, Santo. II pensiero storico classico, p.164.

25 POLIBIO. Histórias, XII, 27, p.522.

26 POLIBIO. Histórias, XII, 27, p.522.
} 
Entre os latinos, a abordagem da relação res / verba ganha novos contornos, na medida em que a discussão acerca do caráter retórico da história é alçada ao primeiro plano. Há, na comparação com os historiadores gregos, um deslocamento parcial de ênfase, da produção da presença via autópsia ou escrutínio cuidadoso de relatos orais para a construção de lições gerais moralizantes, o que se associa em grande medida ao caráter cerimonial atribuído à história em Roma. Não que os gregos tivessem preterido a meditação sobre o caráter retórico da história, ou destinado pouca atenção à questão das lições formuladas a partir do exame de acontecimentos passados. Segundo o argumento de Luciano Canfora, pode-se perceber, da parte de Tucídides, um "esforço de elaboração retórica" na História da Guerra do Peloponeso, onde o "espaço reservado à palavra retoricamente elaborada é amplíssimo, em grande medida mais que em Heródoto". ${ }^{27}$ Ademais, discípulos de Isócrates, como Teopompo e Éforo, fizeram da retórica o princípio condutor na composição de histórias. ${ }^{28}$ No que diz respeito à tópica da utilidade, tanto Tucídides como Políbio realçam sua centralidade na história: "mas, se todos os que quiserem examinar com clareza o que aconteceu (e o que porventura, conforme o humano, será de novo igual ou semelhante ao acontecido) os julgarem úteis, será o suficiente", afirma Tucídides; 29 "a melhor educação para a realidade da vida é a experiência que resulta da história pragmática", define Políbio. ${ }^{30}$

Existem, porém, diferenças contundentes no que diz respeito à comparação do tratamento da tensão entre logos e ergon em Tucídides e da tensão entre res e verba em Salústio e Cícero, assim como à comparação da concepção de utilidade em Tucídides e Políbio e nos historiadores latinos. Diferentemente dos gregos, estes esboçam uma sutil problematização daquilo que Luiz Costa Lima chama de "determinação aporética da escrita da história", ou seja, a compreensão desta como inscrição da verdade, determinação do que é necessariamente fugidio. ${ }^{31}$ Diz Salústio, em sua Conjuração de Catilina:

parece-me que o ofício de quem escreve as coisas acontecidas [res gestas scribere] seja árduo: primeiramente porque se deve adequar as palavras aos fatos; depois porque diante das críticas feitas, a maioria pensa que as palavras foram ditas por malevolência e ódio; quando se faz menção da grande virtude

27 CANFORA, Luciano. La storiografia greca, p.22. Posição similar é defendida por: HORNBLOWER, Simon. "Narratology and Narrative Techniques in Thucydides". In; HORNBLOWER, Simon. Greek Historiography. Oxford: Clarendon Press, 1994, p.165.

28 Cf. CANFORA, Luciano. La storiografia greca, p.22.

29 TUCÍDIDES. História da Guerra do Peloponeso, 22, p.81.

30 POLIBIO. Histórias, I, 35, p.112.

31 COSTA LIMA, Luiz. História. Fic ção. Literatura, p.39. 
e da glória dos valorosos, aceita de bom grado aquilo que julga capaz de fazer, enquanto considera inventado ou falso o que supera suas possibilidades. ${ }^{32}$

Aqui, diferentemente do tratamento tucididiano da questão, Salústio não recorre ao procedimento da autópsia como solução para seu impasse, que é tratado como tensão constitutiva, no que diz respeito à verificação das dificuldades de adequar palavras e fatos e de constatar uma apropriação que não seja tida como maledicente, partidária ou puramente laudatória. A preocupação com a produção da presença, embora exista, é tomada como um dos meios capazes de incidir no fim almejado: a educação moral dos ouvintes / leitores. Como analisarei adiante, Cícero, no De Oratore, abordará a questão em termos próximos de Salústio - ou, reconhecida a anterioridade do escrito ciceroniano, pode-se dizer que os termos de Salústio aproximamse daqueles do filósofo latino.

A outra diferença fundamental diz respeito à questão da utilidade do relato histórico. Para Tucídides e Políbio tratava-se menos da definição de lições morais generalizantes que da proposição de ensinamentos práticos, de caráter político e militar, capazes de atuar como "memória artificial" para homens que porventura viessem a se encontrar diante de situações semeIhantes às descritas nas histórias. ${ }^{33}$ Segundo Charles Fornara, o primeiro a introduzir lições moralizantes de caráter geral nas histórias foi Xenofonte - ${ }^{34}$ não é de se estranhar, nesse sentido, que tanto ele quanto Plutarco tenham sido, no Renascimento florentino, os historiadores gregos mais difundidos. ${ }^{35}$ Para os latinos, a produção de uma lição de virtus pelo ouvinte ou leitor do relato histórico era o ponto crucial. Daí a relevância atribuída à questão do tratamento retórico da expositio rerum gestarum: se não houvera atualização de efeitos persuasivos junto a leitores e ouvintes, o relato será incapaz de fornecer lições adequadas.

Cícero, no De Oratore (55 a. C.), alude a utilidade do relato histórico em sentença memorável e exaustivamente repetida até os nossos dias: "a história é testemunha dos séculos, luz da verdade, vida da memória, mestra da vida, mensageira do passado". Menor atenção, porém, foi dedicada pela posteridade à pergunta que fecha a ilustre passagem: "que voz, se não a do orador, pode torná-la imortal?". ${ }^{36}$ A seguir, analisarei a maneira com que Cícero concebe a relação entre história e retórica, e sua ênfase na figura do orador prudente - simultaneamente conhecedor da matéria e perito na ars

32 SALÚSTIO. La congiura di Catilina / Bellum Catilinae. Lorenzo Barbera Editore, 2006, 3, 2, p.5.

33 Cf. WALBANK, Frank W. "Polybius and the past". In: Polybius, Rome and the Hellenistic World. Essays and Reflections. Cambridge: Cambridge University Press, 2002, p.179.

34 Cf. FORNARA, Charles. The Nature of History in Ancient Greece and Rome, p.107.

35 Cf. FRYDE, E. B. Humanism and Renaissance Historiography. London: The Hambledon Press, 1983, p.24.

36 CICERO, Marco Túlio. De Oratore, II, 36. Emprego a tradução de J acyntho Lins Brandão. In: HARTOG, François. A história de Homero a Santo Agostinho, p.181. 
dicendi - como aquele apto a ornar a expositio rerum gestarum segundo os modelos gregos.

Procurando esmiuçar os termos da possível relação entre memoria rerum gestarum e retórica, Cícero, pela voz do personagem Antonio, traça no livro II do diálogo De Oratore uma genealogia das atividades de registro das coisas passadas entre os romanos, com o intuito de delimitar, através da comparação dessas práticas com o legado grego, aquilo que ele considera a especificidade da história: ser uma construção de palavras e coisas devidamente ornada pela voz do orador, condição para que o registro dos acontecimentos passados possa revelar alguma utilidade pública. Diz Antonio que "a história [historia] não era mais que a confecção de anais [annalium confectio]"37, e mesmo os gregos antes de Heródoto e Tucídides haviam escrito como Catão, Fábio Pictore Pisão - famosos, segundo ele, tanto por suas valiosas notas sobre acontecimentos passados como pela crueza e ausência de adornos em seus relatos. ${ }^{38}$ "Muitos seguiram essa forma de redação", prossegue ele, "que, sem ornamento algum, deixou apenas os monumentos relativos aos tempos, aos homens, aos lugares, aos acontecimentos". ${ }^{39}$ Tais registros, porém, por sua rudeza e falta de elegância, não são vistos como adequados à produção de ensinamentos gerais, capazes de orientar as ações dos homens. Era preciso, segundo Antonio, que, a exemplo dos gregos, os romanos dispusessem e ornassem suas histórias segundo as regras da arte retórica, para que tais registros fossem capazes de produzir nos ouvintes e leitores os efeitos desejados.

Antonio define dois modelos que, segundo ele, deveriam ser emulados pelos romanos interessados em compor histórias. São ele Heródoto e Tucídides:

[...] entre os gregos, homens eloquentíssimos, que se mantiveram longe da prática forense, dedicaram-se a outras atividades ilustres e sobretudo a escrever história [historiam scribendam]. Por exemplo, o famoso Heródoto, que foi o primeiro a ornar esse gênero, não se ocupou absolutamente de processos, segundo a tradição que recebemos; todavia, tanta é sua eloqüência que eu, certamente, tanto quanto posso entender o que se escreve em grego, me regalo extremamente com ela. Depois dele, Tucídides, segundo minha opinião, ultrapassou facilmente a todos pela arte da sua linguagem [dicendi artificio]: ele é tão denso em numerosos domínios, que conseguiu ter quase tantas palavras [verborum] quanto pensamentos [sententiarum]; mais ainda, sua dicção tem tanta proporção e tensão, que não se sabe se o fato [res] dá brilho ao estilo [oratione] ou a língua [verba] ao pensamento [sententiis]. [...] em seguida, saídos do que era como que uma brilhantíssima escola de retórica, dois homens de superior

37 CICERO, Marco Túlio. De Oratore, II, 52, p.145.

38 CICERO, Marco Túlio. De Oratore, II, 53, p.145.

39 CICERO, Marco Túlio. De Oratore, II, 53, p.145. 
talento, Teopompo e Éforo, sob o impulso de seu mestre Isócrates, consagraram-se à história (grifos meus). ${ }^{40}$

Heródoto é tido como o primeiro a ornar o gênero, a expositio rerum gestarum, e Tucídides como o maior de todos, por seu dic endi artificio. Percebe-se a ênfase atribuída ao ornato, à fluência e à riqueza de expressão - precisamente o que diferencia, para Antonio, eloqüentes exornatores de simples narratores, responsáveis pelo registro de fatos passados sem brilho algum. ${ }^{41}$ Como observa Charles Fornara, 0 verbo latino ornare "significa algo mais que adornar superficialmente, decorar, embelezar. [...] Ornare em si mesmo é tomar um fato e, a partir dele, montar uma cena, desenvolvendo suas potencialidades latentes". ${ }^{42}$

Um ponto deve ser destacado na passagem acima, por trazer elementos cruciais para a compreensão do próximo passo argumentativo de Antonio, a saber, a definição da história como uma construção de fatos e palavras [rebus et verbis]: ${ }^{43}$ trata-se da tematização da especificidade da relação entre res e verba, através dos pares res $x$ oratione, verba $x$ sententia. Reagrupando-os pelo critério da semelhança, não do antagonismo, é possível chegar a novos pares, a saber: res, sententia $x$ verba, oratione. 0 valor de Tucídides, segundo Antonio, estaria exatamente no entrelaçamento destas oposições, de modo a tornar indistinguíveis ars dicendi e rerum cognitione como aspectos separados do discurso; articulados, torna-se difícil assinalar se é a res que dá brilho à oratione de Tucídides ou se é a verba a iluminar seus pensamentos [sententiis]. Nesse sentido, pode-se dizer que o valor da história ornada - a única, para Cícero, digna desse nome - repousa na supressão retórica da oposição entre res e verba, não pelo recurso à autópsia, que sequer é mencionada por Antonio, e sim pela prescrição de uma unidade discursiva entre verba e rerum cognitione, que somente a figura do orador pleno - simultaneamente sábio, prudente e eloqüente - pode alcançar.

Assim, se em Tucídides existe a presunção de que o phronimos é potencialmente o melhor historiador, porser capaz de observare compreender com clareza as variações da realidade sem se deixar levar por simpatias ou partidarismos diversos, conformando a fidúcia necessária à validação do procedimento da autópsia, em Cícero a unidade retórica entre res e verba só pode ser alcançada pelo prudente, um orador eloqüente que seja ao mesmo tempo profundo conhecedor da matéria tratada. Daí a indagação de Antonio, após o término de sua exposição sobre o valor dos historiadores

40 CICERO, Marco Túlio. De Oratore II, 55-57, p.147.

41 CICERO, Marco Túlio. De Oratore, II, 54, p.147.

42 FORNARA, Charles William. The Nature of History in Ancient Greece and Rome, p.136.

430 uso do vocábulo "fato", aqui, deve ser tomado em sentido amplo, como acontecimento, ou "coisas acontecidas". 
gregos: "não vedes a que ponto a história é função do orador? Não sei se a mais importante, pela riqueza e pela variedade do estilo". ${ }^{44}$

Logo a seguir, Antonio destacará a falta de atenção dos tratados de retórica à história, a qual, segundo ele não é "em lugar algum especialmente contemplada pelos preceitos dos retores". ${ }^{45}$ Isto se deve, segundo ele, ao fato de as leis da história serem de conhecimento geral, estando por isso "diante dos nossos olhos". São as seguintes as leis da história elencadas por Antonio:

Com efeito, quem ignora que a primeira lei da história é não ousar dizer algo falso? Em seguida, não ousar dizer algo que não seja verdadeiro? Que não haja, ao se escrever, qualquer suspeita de complacência? Nem o menor rancor? ${ }^{46}$

As leis da história constituem premissas necessárias, sem as quais mesmo uma narrativa convenientemente ornada não se revelará eloqüente e persuasiva, precisamente por carecer de conhecimento da matéria. Como diz Emanuele Narduci, "a abundância da matéria", para Cícero, "produz a riqueza das palavras, e a honestidade (honestas) dos argumentos tratados conferem uma natural beleza à expressão do orador". ${ }^{47}$ Por esta razão não é possível extrair lições úteis do que não aconteceu, ou do que foi deturpado por rancor ou complacência. Assim como Tucídides, Cícero, por um viés diverso, embora em alguma medida complementar àquele do historiador ateniense, atribui relevo à questão da fidúcia, não pelo recurso ao argumento de autoridade do testemunho ocular prudente, mas através da construção retórica de um caráter (ethos) irretocável, ${ }^{48}$ fundamental para que haja a produção de uma "representação que coloca diante dos olhos". Diz Alcir Pécora acerca do panegírico, subgênero epidítico assim como a história e outras formas historiográficas:

trata-se pois de um discurso que autoriza a verdade desses feitos. 0 seu recurso fundamental para tanto é a representação que os coloca diante dos olhos do leitor, por meio de uma composição assentada na vivacidade do que se narra, de tal modo que se imagina testemunhado pela vista, no exato presente da leitura. ${ }^{49}$

44 CICERO, Marco Túlio. De Oratore, II, 62, p.151.

45 CICERO, Marco Túlio. De Oratore, II, 62, p.151.

46 CICERO, Marco Túlio. De Oratore, II, 62, p.151.

47 NARDUCCI, Emanuele. Cicerone e l'eloquenza romana. Bari: Laterza, 1997, p.65.

48 Digo que são aspectos complementares porque também em Tucídides a construção do ethos é retórica, uma vez que o que dá fé não é apenas o testemunho ocular em si, mas também a prudência de quem testemunha, a qual é atestada pelos ouvintes e leitores que precisam reconhecê-lo como tal. No entanto - e aí reside a diferença fundamental -, Tucídides não tematiza esta construção do ethos como elemento decisivo da história, enquanto Cícero, na medida em que subordina a ars historica ao sistema retórico, implicitamente atribui um lugar próprio à delimitação do ethos.

49 PÉCORA, Alcir. "A história como colheita rústica de excelências". In: SCHWARTZ, Stuart B.; PÉCORA, Alcir (org.). As excelências do govemador. São Paulo: Companhia das Letras, 2002, p.49. 
A atinência às leis da história, nesse sentido, é incapaz por si mesma de "dar fé" ao que é narrado, uma vez que a construção de um bom ethos é ela mesma retórica, sendo parte importante da inventio - seu lugar apropriado é o exórdio, que deve buscar a atenção e captar a benevolência dos ouvintes. ${ }^{50}$ Daí a afirmação de Antonio de que "esses fundamentos são conhecidos por todos, mas a própria construção repousa nos fatos e nas palavras [exaedific atio posita est in rebus et verbis]". ${ }^{51}$ Como argumenta Luiz Costa Lima, "o De Oratore, concebido e redigido em 55 a.C., revelava que, mesmo em Roma, a maior ênfase na eloqüência não dissolvia a nota específica do historiador". ${ }^{52}$ Isto não quer dizer, porém, que "Luciano e Cícero expunham o historiador fora do puro domínio da retórica", ${ }^{53}$ muito pelo contrário: toda a ênfase do filósofo romano - e também do sátiro de Samósata, como analisarei adiante -, voltava-se para a elevação da expositio rerum gestarum segundo preceitos retóricos articulados a partir da leitura atenta e minuciosa dos historiadores gregos, especialmente Tucídides. ${ }^{54}$ Dito de outro modo, Cícero defende que, embora as leis da história não possam ser abandonadas, elas, em si, não garantem a elevação do gênero; somente o orador pleno, um homem prudente, ${ }^{55}$ está apto a produzir uma história rica em ensinamentos, útil por ser capaz, inicialmente, de deleitar seus ouvintes / leitores e em seguida de movê-los no sentido da ação virtuosa. ${ }^{56}$

Seguindo o mesmo viés analítico, Luciano de Samósata, embora defenda em seu opúsculo Como se deve escrever a história que "do mesmo modo que admitimos que o historiador deve ter como objetivos a franqueza e a verdade, assim também o primeiro e único objetivo de sua linguagem é explicar claramente os fatos e fazê-los aparecer em plena luz"57, argumenta que "será necessário algum sopro poético para inflar as velas com bons

50 Cf. MONTEFUSCO, Lucia Calboli. Exordium Narratio Epilogus. Studi sulla teoria retorica greca e romana delle parti del discorso. Bologna: CLUEB, 1988, p.3.

51 CICERO, Marco Túlio. De Oratore, II, 63, p.151.

52 COSTA LIMA, Luiz. História. Ficção. Literatura, p.98.

53 COSTA LIMA, Luiz. História. Ficção. Literatura, p.100.

54 Cf. NARDUCCI, Emanuele. Cicerone e l'eloquenza romana, p.23.

55 Cícero vislumbra na figura do orador pleno - simultaneamente sábio, prudente e eloqüente - a desejável unidade entre filosofia e retórica. Cf. CAPE J R., Robert W. "Cicero and the Development of Prudential Practice at Rome". In: HARIMAN, Robert (org.). Prudence. Classical Virtue, Postmodern Practice. Pennsylvania: The Pennsylvania State University Press, 2003, p.39; NEDERMAN, Cary J. "Rhetoric, reason, and republics: Republicanisms - ancient, medieval, and modern". In: HANKINS, J ames (org.). Renaissance Civic Humanism. Cambridge: Cambridge University Press, 2000, p.252.

56 Docere, delectare, movere: de acordo com os tratados clássicos, estas seriam as três finalidades da retórica, sendo a primeira associada ao gênero de estilo simples, a segunda ao gênero nobre e a terceira ao gênero médio. A história, por ser compreendida como subgênero epidítico com alguma proximidade do gênero deliberativo, não deveria se fixar exclusivamente em um dos três gêneros de estilo. No que diz respeito à narração, o gênero simples deveria ser privilegiado. Já no exórdio e nas digressões, o gênero médio seria o mais apropriado, visando ao deleite e à captação da benevolência do auditório ou dos leitores. Na peroração, responsável por mover os homens à ação, o gểnero de estilo conveniente seria o nobre. Cf. MONTEFUSCO, Lucia Calboli. Exordium Narratio Epilogus, p.7. "Nell'orator poi la dottrina, pur presentata sempre come caratteristica di Antonio, subisce un'evouzione nella conessione tra queste qualità o compiti dell'oratore e i tre stili del discorso, per cui al docere corrisponderebbe lo stilo piano, ao delectare il medio, al movere l'elevato".

57 LUCIANO. Como se deve escrever a história. In: HARTOG, François. A história de Homero a Santo Agostinho, 44, p.225. Tradução de J acyntho Lins Brandão. 
ventos e elevar a nau sobre a crista das ondas". ${ }^{58}$ Daí sua preocupação com a disposição e com o adornamento do discurso:

justamente essa é também a tarefa do historiador: ordenar os acontecimentos de forma bela e mostrá-los da maneira mais clara possível. Quando, escutando-o, alguém julga ver o que é dito e em seguida o elogia, então, sim, sua obra está perfeita, tendo ele recebido um elogio apropriado a um Fídias da história (grifo meu)..$^{59}$

Em Luciano, como em Cícero, a produção da presença advém do domínio das sutilezas e habilidades da arte retórica. A visualização do que é dito decorre da consecução de um efeito desejado, insinuado em movimentos sutis concernentes à mobilização de lugares-comuns, às medidas dispositivas e às figuras da elocutio empregadas. Constitui-se, assim, uma unidade discursiva calcada na presunção da indissociabilidade entre o conhecimento da matéria e sua exposição apropriada, incidindo em relato pleno, decoroso, útil e honesto. Daí que o lugar da história no sistema retórico seja, senão esmiuçado, ao menos aludido nos tratados clássicos de arte retórica, especialmente nas sessões destinadas ao exame do gênero epidítico. ${ }^{60}$

Voltado para a produção de lições edificantes, úteis e honestas, onde, através do encômio ou vitupério de homens e cidades, ficassem claros 0 caminho da virtude e os perigos do vício, o gênero epidítico englobava uma série de subgêneros: o panegírico, a laudatio funebris, a biografia exemplar, a crônica, a história, entre muitos outros. Como argumenta Lucia Calboli Montefusco, "no gênero epidítico o uso da narratio se justifica mais razoavelmente", em comparação com seu emprego no gênero deliberativo. ${ }^{61}$ Daí que, no De Inventione, Cícero trate da história em seção destinada à narrativa, definindo-a como a exposição de gesta res, ab aetatis nostrae memoria remota - coisas acontecidas em tempos distantes, segundo nossa memória. ${ }^{62}$ Ela vem incluída, juntamente com a fabula - "narração própria da tragédia e da poesia, distante da verdade e da verossimilhança" - e o argumentum - "narração própria da comédia, distante da verdade mas verossímil"63 -, na classe de narrativas concernentes aos negotiis, não às pessoas, categorias que por sua vez pertencem ao terceiro grupo de uma

58 LUCIANO. Como se deve escrever a história, 45, 227.

59 LUCIANO. Como se deve escrever a história, 51, p.231.

60 Os tratados gregos e latinos dividiam a retórica em quatro ou cinco grandes partes: a inventio (heurésis), ou busca dos argumentos; a dispositio (táxis), ou ordenamento dos argumentos num plano regrado; a elocutio (lexis), ou definição de gêneros de estilo e figuras; a pronuntiatio (hypocrisis), ou efetivação dos discursos. Alguns, como Cícero, acrescentavam a memória. Definiam também três gêneros do discurso: judicial, ou a retórica dos tribunais; deliberativo, retórica das assembléias e discussões públicas; epidítico, voltado para o deleite da platéia.

61 MONTEFUSCO, Lucia Calboli. Exordium Narratio Epilogus, p.36.

62 CICERO, Marco Túlio. De Inventione. Madrid: Gredos, 1997, I, 19.

63 Cf. MONTEFUSCO, Lucia Calboli. Exordium Narratio Epilogus, p.46. 
divisão tríplice: (a) narrativa que inclui a própria causa, fundamento da controvérsia; (b) narrativa que contém uma divisão externa à causa, cuja finalidade principal é a acusação; (c) narrativa alheia às causas civis, cujo objetivo principal é agradar, embora sirva também como exercício útil para 0 falar e 0 escrever. ${ }^{64}$

As premissas gerais do gênero epidítico são estabelecidas e analisadas por Cícero em De Partitione Oratoria: "tudo o que está associado à virtude deve ser louvado e tudo o que está associado ao vício deve ser vituperado", diz ele. 65 "Mas este tipo de discurso", prossegue, "consiste em narrar e exibir ações passadas, sem empregarargumentos, e seu estilo busca influenciar suavemente as emoções, ao invés de buscar convencimento e aquisição de provas. Ele não estabelece proposições que são duvidosas; ao contrário, ele amplifica o que é certo, ou tido por certo". ${ }^{66}$ Como o objetivo claro é o de deleitar a audiência, prossegue ele, o orador deve buscar um "ritmo capaz de satisfazer os ouvidos como o que se pode chamar de harmonia verbal", ${ }^{67}$ o que corresponde ao gênero de estilo médio. Este ritmo, no caso da história, deve emular a autoridade de Heródoto e Tucídides, perfazendo um "tipo de discurso agradável, fácil, abundante, com frases engenhosas e palavras harmoniosas", de acordo com definição proposta pelo filósofo romano no Orator. ${ }^{68}$

Como notam Perelman e Tyteca,

os discursos epidíticos constituem uma parte central da arte de persuadir [.. ]. A eficácia de uma exposição tendente a obter dos ouvintes uma adesão suficiente às teses apresentadas, só pode ser julgada pelo objetivo que o orador se propõe. A intensidade da adesão [...] muitas vezes será reforçada até que a ação, que ela deveria desencadear, tenha ocorrido. ${ }^{69}$

O discurso epidítico, nesse sentido, reforça "uma disposição para a ação ao aumentar a adesão aos valores que exalta", ${ }^{70}$ aproximando-se, portanto, do gênero deliberativo, sem confundir-se com ele. Assim, 0 ato de deleitara audiência, a que a história deveria visar inicialmente, não era tomado como um fim em si mesmo, isto porque havia claramente a prescrição de uma finalidade pedagógica dos relatos, na medida em que se esperava que estes visassem sobretudo à afirmação do útil. Define-se, assim, uma estreita

64 Esta mesma divisão se faz presente na Retórica a Herênio e em Quintiliano. Cf. MONTEFUSCO, Lucia Calboli. Exordium Narratio Epilogus, pp.45-6.

65 CICERO, Marco Túlio. De Partitione Oratoria. Cambridge and London: Harvard University Press, 2004, XXI, 71.

66 CICERO, Marco Túlio. De Partitione Oratoria, XXI, 71.

67 CICERO, Marco Túlio. De Partitione Oratoria, XXI, 72.

68 CICERO, Marco Túlio. Orator. Madrid: Alianza Editorial, 2004, 42, p.47.

69 PERELMAN, Chaïm; TYTECA, Lucie Olbrechts. Tratado da Argumentação. A Nova Retórica. São Paulo: Martins Fontes, 2002, pp.54-5.

70 PERELMAN, Chaïm; TYTECA, Lucie Olbrechts. Tratado da Argumentação. A Nova Retórica, pp.55-6. 
relação entre os gêneros epidítico e deliberativo, embora, ao menos até 0 século $\mathrm{XV}$, seus contornos se mantenham nítidos e bem traçados. ${ }^{71}$

0 argumento-tipo do discurso epidítico é a amplificação. Por amplificação entendia-se uma forma de argumentação pautada na elevação da nobreza de algo ou alguém, ou no destaque dos vícios de algo ou alguém, como forma de "instigar o auditório por meio do lugar-comum"72 e de compor o caráter virtuoso ou vicioso do sujeito através do elogio ou censura. ${ }^{73}$ Os preceitos relativos ao encômio e ao vitupério são compartilhados pelo panegírico e pela história, e Cícero os enumera no livro II do De Oratore $(45,46)$. A história, porém, possui algumas regras próprias, que tanto dizem respeito ao tratamento da matéria quanto à elocutio. Diz Antonio:

a inteligência dos fatos requer a ordem dos tempos e a descrição dos lugares. Pede também, já que em fatos importantes e dignos de memória se espera que haja primeiro deliberações, depois execução e em seguida resultados, que sobre as deliberações seja indicada qual é aquela que o autor aprova; sobre os feitos, que se declare não só o que se fez ou se disse, mas também de qual modo; e, quando se fala do resultado, que se desenvolvam todas as causas que se devem ao acaso, à sabedoria ou à temeridade - e não se fale só dos feitos dos próprios homens, mas, com relação aos que se distinguem pela reputação e pelo nome, também da vida e do caráter de cada um. Quanto à economia da linguagem [verborum autem ratio], deve-se perseguir um gênero oratório difuso e arrastado, que flua regularmente como uma certa suavidade, sem essa aspereza própria ao tribunal e sem os aguilhões que as fórmulas têm no fórum (grifos meus). ${ }^{74}$

São estes, para Antonio, os preceitos concernentes à composição da história segundo as regras da arte retórica, princípios que envolvem não apenas o tratamento do estilo como também a apreciação da matéria, através da especificação dos três tipos de causas que devem ser atribuídas às ações humanas; da necessidade de não apenas descrever o que se fez ou disse, mas também de definir os modos com que algo foi feito ou dito; da defesa de que a vida e caráter dos homens sejam abordados como aspectos constitutivos dos próprios fatos.

Embora tratadistas subseqüentes como Quintiliano e Dionísio de Helicarnasso tenham direcionado o debate para outros aspectos, como a proximidade entre história e poesia, ${ }^{75}$ a asseveração da dignidade da história sempre esteve associada à mobilização da tópica da utilidade. Daí

71 Cf. KAHN, Victoria. Rhetoric, Prudence, and Skepticism in the Renaissance. Ithaca and London: Cornell University Press, 1985, p.39. "But the distinction between deliberative and demonstrative rhetoric breaks down in the works of the Quattrocento humanists not only because epideictic can be viewed as urging a course of action, but also because the deliberation involved in reading is itself understood as a form of the deliberation that leads to action".

72 AD. Retórica a Herênio. São Paulo: Hedra, II, 47, p.143.

73 Cf. LECHNER, J oan Marie. Renaissance Concepts of the Commonplaces. New York: Pageant Press, 1962, p.101.

74 CICERO, Marco Túlio. De Oratore, II, 63-64, p.151.

75 Cf. COSTA LIMA. História. Ficção. Literatura, pp.100-104. 
a afirmação de Luciano de Samósata de que "a utilidade é o fim da história, de modo que, se alguma vez, de novo, acontecerem coisas semelhantes, poder-se-á, diz ele, consultando-se o que foi escrito antes, agir bem em relação às circunstâncias que se encontram diante de nós". ${ }^{76}$ Os termos são claramente tucididianos, e remetem à famosa passagem do capítulo 22 do livro I, onde o historiador ateniense afirma que seu relato constitui "aquisição para sempre".

Ao afirmar o produto de sua operação como ktêma (aquisição, patrimônio) para sempre, Tucídides atribui a seu escrito um caráter monumental: por ser o registro da guerra, a história se afirma como presença, cuja validade em si, cuja grandeza dos erga, registrada em logos a que se atesta fidúcia pela autópsia, produzirá lições úteis àqueles que se dispuserem a destrinchá-la. Como nota François Hartog, Tucídides opera aí um deslocamento fundamental em relação a Heródoto, do kléos ao ktema:

Heródoto pôs mãos à obra para impedir que todas as marcas da atividade dos homens se apagassem (tornando-se akléa), deixando muito rapidamente de serem contadas. Tucídides, por seu lado, escolhendo 'escrever' uma guerra que ele sabia dever ser 'a maior' de todas, apresenta sua narrativa como 'ktêma para sempre', isto é, patrimônio para sempre. Do kléos ao ktêma, o deslocamento é sensível. [...] Daí em diante não se trata mais de preservar do esquecimento as ações valorosas, mas de transmitir às gerações futuras um instrumento de inteligibilidade de seu próprio presente. ${ }^{77}$

Este sentido de patrimônio, aquisição, monumento, adquire uma dimensão ainda mais expressiva com os romanos, para quem a história era sempre entendida como res gestae populi Romani. ${ }^{78}$ Como percebe Charles Fornara, diferentemente dos gregos, "Fábio, Postumus, Catão, Fannio, Asellio e outros escreveram sobre sua cidade-estado como membros da elite dirigente". ${ }^{79}$ Daí que, por exemplo, a questão dos conflitos internos (stasis), de modo algum um assunto considerado memorável e por isso digno de nota entre os historiadores gregos, torne-se um objeto privilegiado nas considerações dos romanos.

Uma das principais críticas de Cícero aos primeiros narratores latinos das coisas acontecidas dizia respeito à dificuldade de se extrair lições edificantes de relatos pouco ornados, rústicos e meramente descritivos. Nesse sentido, Salústio, profundo conhecedor dos oradores gregos, pode ser considerado como o primeiro dentre os romanos a compor uma obra histórica em consonância com os preceitos ciceronianos, embora fosse inimigo político do filósofo - o que, como percebe Santo Mazzarino, não o

76 LUCIANO. Como se deve escrever a história, 42, p.225.

77 HARTOG, François. O Espelho de Heródoto, p.28.

78 Cf. FORNARA, Charles. The Nature of History in Ancient Greece and Rome, p.41.

79 FORNARA, Charles. The Nature of History in Ancient Greece and Rome, p.54. 
impediu de atribuir a Cícero um papel de destaque na luta contra Catilina..$^{80}$ Sua Conjuração de Catilina, claramente inspirada em motivos tucidideanos, pode ser considerada uma tentativa de construir um legado romano para sempre apoiado em dois pilares: a antiga virtus do período anterior à Segunda Guerra Púnica, associada a homens que "com estas duas atitudes, a audácia na guerra e a eqüidade nos momentos de paz, governavam a si mesmos e à república", 81 e os exemplos de virtude no mar de corrupção da Roma de Salústio, especificamente Catão e César, "homens de notável virtude, e por caráter opostos". 82

Eis um tema que Maquiavel retomará em 0 Príncipe: a complementaridade entre ímpeto e prudência. Catilina só pôde ser derrotado, argumenta Salústio, porque dois homens de temperamentos distintos atuaram em colaboração - Catão, homem severo, modesto e decoroso, que preferia ser bom a parecer bom; César, responsável por inúmeras glórias e conquistas no comando de suas legiões, liberal, o "refúgio dos pobres", além de estimado pela generosidade..$^{83} \mathrm{~A}$ prudência, na Conjuração de Catilina, é vista como a principal dentre as virtudes, aquela responsável tanto pela articulação da concórdia civil - sendo por isso fundamentalmente justa -, como pelo equilíbrio dos apetites:

os homens mais prudentes eram os mais ocupados nos negócios políticos, ninguém exercitava a mente sem o corpo, os melhores preferiam agir a falar [...]. Tanto na paz como na guerra os bons costumes eram cultivados: a concórdia era máxima, mínima a avidez. ${ }^{84}$

Já o ímpeto é associado à bravura e à coragem, especialmente no que concerne ao domínio das habilidades militares.

Salústio, sem perder de vista a lição honesta afirmada no proêmio de caráter filosófico - "a glória das riquezas e da beleza é efêmera e frágil; a virtus é um bem esplêndido e eterno"85 -, constrói, em movimentos bem marcados, sua exposição da conjuração de Catilina, procurando seguir tanto o preceito tucididiano da akríbeia como as regras elencadas no De Oratore sobre o tratamento da matéria e o estilo adequado à história: a narrativa é breve e suave, indo dos tempos antigos, descritos rapidamente como na parte "arqueológica" da história de Tucídides, aos tempos atuais, delineados em minúcias; discursos diretos expõem as motivações dos personagens, e possibilitam a demarcação de pontos de vista diversos; 0 acaso, a sabedoria e a temeridade são os critérios explicativos fundamentais das ações

80 Cf. MAZZARINO, Santo. II pensiero storico clássico, vol. 3, p.17.

81 SALUSTIO. La congiura di Catilina / Bellum Catilinae, 9,3, p.13.

82 SALUSTIO. La congiura di Catilina / Bellum Catilinae, 53, 6, p.81.

83 Cf. SALUSTIO. La congiura di Catilina / Bellum Catilinae, 54, p.83.

84 SALUSTIO. La congiura di Catilina / Bellum Catilinae, 8-9, p.13.

85 SALUSTIO. La congiura di Catilina / Bellum Catilinae,1, 4, p.3. 
dos agentes; a amplificação da virtudes de César e Catão, assim como dos vícios de Catilina e seus asseclas, demarcam nitidamente o caráter destes, encadeando-se com as ações - as amplificações constroem o ethos em sentido retórico, mobilizando lugares-comuns de aceitação universal; trata-se, nesse sentido, menos da tentativa de delimitar as motivações dos agentes que da produção de hipérboles capazes de incidir na atenção dos ouvintes e leitores. Assim, o relato ornado, repleto de exemplos, sentenças, amplificações e figuras engenhosas deleita num primeiro momento para, em seguida, persuadir os ouvintes e leitores no sentido da ação imitativa, segundo os modelos virtuosos apresentados.

Levando-se em conta o tratamento de Cícero e Salústio da ars historica, modelos que Tito Lívio toma para si, não é de se estranhar que ele, em seu Ab Urbe Condita, defina a história como monumento:

o que principalmente há de são e fecundo no conhecimento dos fatos [cognitione rerum] é que consideras todos os modelos exemplares, depositados num monumento, em plena luz: daí colhes para ti e para teu estado [rei publicae] 0 que imitar; daí evitas o que é infame em sua concepção e em sua realização. ${ }^{86}$

Concebida como "texto-monumento" - ${ }^{87}$ oposto à "palavra evento" do aedo, para empregar terminologia de Florence Dupont -, registro utilitário da res gestae populi Romani, esperava-se da história que iluminasse os homens, fornecendo, através de exemplos numerosos, modelos virtuosos a serem imitados ou condutas viciosas a serem rejeitadas. 0 exemplo, retoricamente, torna claro o que é obscuro; ajuda na construção do verossímil; torna a matéria mais ornada; finalmente, como se pode ler na Retória a Herênio, "coloca-as diante dos olhos, quando expressa tudo de modo tão perspícuo que eu diria ser quase possível tocar com a mão". ${ }^{88} 0$ monumento da história é, nesse sentido, uma efetiva presença tangível, capaz de orientar, como aquisição para sempre, inúmeras gerações.

86 TITO LIVIO. Ab Urbe Condita, Proemio, 10, p.207. In: HARTOG, François. A história de Homero a Santo Agostinho. Tradução de J acyntho Lins Brandão.

87 Cf. DUPONT, Florence. L'invention de la littérature. Paris: La Découverte, 1998, p.36.

88 Cf. AD. Retória a Herênio, IV, 62, p.297. 